\title{
Barriers to Confidentiality Protection in Adolescent Healthcare: A Survey of Serbian Primary Healthcare Paediatricians and Gynaecologists
}

\author{
Vida Jeremic Stojkovic ${ }^{1}$, Bojana Matejic ${ }^{2}$, Smiljana Cvjetkovic ${ }^{1}$, Tatjana Gazibara ${ }^{3}$ \\ ${ }^{1}$ Department of Humanities, Faculty of Medicine, University of Belgrade, Belgrade, Serbia, ${ }^{2}$ Institute of Social Medicine, \\ Faculty of Medicine, University of Belgrade, Belgrade, Serbia, ${ }^{3}$ Institute of Epidemiology, Faculty of Medicine, University of \\ Belgrade, Belgrade, Serbia
}

Correspondence: vidajeremic@yahoo.com; Tel.: + 38160636 1076; Fax.:+ 381113636300381113636300

Received: December 9. 2019; Accepted: February 10, 2020

\begin{abstract}
Objective - To explore the perceived barriers to confidentiality of adolescent patients among paediatricians and gynaecologists who work in the primary healthcare setting in Belgrade, Serbia. Materials and Methods - A cross-sectional survey was carried out in 13 primary healthcare institutions in Belgrade, Serbia. A total of 152 paediatricians and gynaecologists filled a self-administered questionnaire. The study instrument was developed for the purpose of this study. Beside socio-demographic characteristics, the questionnaire included a 5-point Likert's scale to assess the respondents' degree of agreement with potential barriers to confidential healthcare services. Results were analyzed using t-test, Chi-square test and linear regression models. Results - The majority of respondents $(67.1 \%)$ indicated that limited time per patient posed a significant barrier to confidential consultation with adolescent patients. This was observed as a consequence of insufficient number of physicians working in primary care institutions. More than a half of respondents recognized a lack of adolescent gynaecologist and inadequate legal definitions as factors that may breach adolescents' right to confidentiality. Conclusion - This study highlights specific obstacles within the healthcare system that need to be addressed in order to respect confidentiality as one of the key characteristics of a safe and supportive adolescent healthcare service. Physicians working with adolescents need to be informed about comprehensive legal guidelines. At a national level, addressing human resources in healthcare could improve adolescent healthcare service.
\end{abstract}

Key Words: Confidentiality • Adolescent Health Services • Physicians • Primary care • Surveys and Questionnaires.

\section{Introduction}

Empirical data from Serbia suggest that in the adolescent population there is insufficient use of contraceptives, while rates of unwanted adolescent pregnancies and induced abortions are high (1-3). Furthermore, age at sexual debut has been decreasing and the risk of sexually transmitted infections (STIs) has been increasing (1-3). In a society undergoing socio-economic transition, these are the key issues that affect health of the adolescents nationwide. As a result, promotion of adolescent reproductive health is of strategic importance.
Similar problems related to the increase of risky health behaviours among adolescents have been observed in other settings challenged by socioeconomic problems(4), primarily because of the increase in rates of unwanted pregnancies, induced abortions and rise in the incidence of STIs. The socio-economic transition also affects the quality of healthcare delivery. Little is known about Serbian adolescents' access to reproductive healthcare services and their satisfaction with the services received. In a study exploring barriers which adolescents in 70 low- and middle-income countries encounter when accessing healthcare services, only 
$10 \%$ of adolescent girls reported visiting their physician in the previous year (5).

When addressing the reasons for reluctance to seek healthcare, adolescents often report feelings of shame, fear that confidentiality might be breached as well as fear of being judged by a physician $(5,6)$. Evidence suggests that adolescents use healthcare services less often compared to other population groups, while this phenomenon has also been observed in the developed countries, such as the United States (6). To increase the availability of healthcare services, a concept of "youth friendly health services" was introduced (7). This initiative offered healthcare services adjusted to the needs of adolescent patients (7). Confidentiality was recognized as the key feature of youth-friendly health services, especially in the field of reproductive health (8). Previous research has shown that adolescents' belief that confidentiality would be granted highly correlated with the increased use of health services and greater willingness to disclose sensitive information to a physician (8). Thus, confidentiality is a critical condition of the effective healthcare in adolescence, particularly within the most advanced healthcare systems (9-12).

However, there are numerous barriers to providing confidential healthcare in the clinical setting: healthcare providers' negative attitudes towards adolescents' right to confidentiality, inadequate education of healthcare providers, legal constraints as well as organizational barriers such as limited time per patient and inadequate protection of medical records (13). Although confidentiality is an inherent feature of the medical profession, many physicians are unsure whether this principle applies to adolescent patients (14). In Serbia, the Law on patients' rights was passed in 2013, granting the right to confidentiality to patients who turn 15 years of age and have a decision-making capacity. However, little is known about specific challenges that Serbian healthcare practitioners encounter while implementing this Law into clinical practice.

The present study aimed to explore the perceived barriers to confidentiality of adolescent patients among paediatricians and gynaecologists who work in the primary healthcare setting in Belgrade, Serbia.

\section{Methods}

\section{Participants and Procedure}

This study is part of a larger cross-sectional survey among Serbian primary care physicians, conducted between November 2017 and August 2018, with aims to explore their knowledge, attitudes and behaviour with regards to confidentiality in adolescent healthcare. The study sample included paediatricians and gynaecologists working at 16 primary healthcare institutions in Belgrade, however three primary healthcare institutions declined their participation in the study.

\section{Study Instrument and Measures}

A questionnaire investigating physicians' attitudes regarding confidentiality of their adolescent patients was developed for the purpose of the study. The questionnaire was developed based on results of a literature review as well as the results of a qualitative study using in-depth interviews in a smaller sample of primary care gynaecologists and paediatricians (15). The first part of the questionnaire included socio-demographic characteristics (age, gender, department, years in practice after graduation, municipality of work place, number of patients per working shift, number of adolescent patients, having an adolescent child).

The second part included 8 statements that represented most important factors that might influence confidentiality decisions, with answers graded on a 5-point agreement scale (from 1 "Strongly disagree" to 5 "Strongly agree"). The respondents were asked to indicate the extent to which they agreed or disagreed with each of the 8 items. The total score of the scale was calculated by summing the points assigned to each questionnaire item, and ranged from 8 to 40 points. The questionnaire was selfadministered and anonymous.

\section{Ethics Statement}

The study protocol was approved by the Ethics Committee of the Faculty of Medicine, University of Belgrade (approval number: 29/VI-1). All gyn- 
aecologists working in gynaecology departments and paediatricians working in school health departments in 13 primary healthcare institutions were invited to participate in the survey. Prior to survey, the participants signed informed consent documents.

\section{Data Analysis}

Data were analysed by means of descriptive and inferential statistics. The statistical package SPSS was used (SPSS Inc, version 22). Descriptive statistics were used to describe the sample characteristics. Differences in socio-demographic characteristics between the groups (gynaecologists and paediatricians) were analyzed by using t-test and Chi-square test. Differences in attitudes between the groups were explored by means of Chi-square test. Univariate and multivariate linear regression models were applied to examine potential factors associated with the total score of questionnaire. The independent variables in the regression models were all socio-demographic characteristics of the respondents. In all analyses, $\mathrm{P}<0.05$ was considered statistically significant.

\section{Results}

\section{Socio-Demographic Characteristics of Respondents}

A total of 152 physicians completed the survey, of which 78 paediatricians from the school health departments and 74 gynaecologists from the women's health departments. Socio-demographic characteristics of the sample and differences between the groups are presented in Table 1. Mean age of the participants was $50.8 \pm 9.0$ years. The vast majority

\section{Table 1. Socio-Demographic Characteristics of the Respondents in the Primary Healthcare Setting}

\begin{tabular}{|c|c|c|c|c|}
\hline Socio-demographic variables & Total & Pediatricians & Gynecologists & P-value ${ }^{*}$ \\
\hline Age (Mean. $\pm S D)$ & $50.8 \pm 9.0$ & $50.6 \pm 10.2$ & $50.8 \pm 7.6$ & $\mathrm{P}=0.751$ \\
\hline Years of work after graduation (Mean. \pm SD) & $23.2 \pm 9.9$ & $22.9 \pm 11.3$ & $23.6 \pm 8.4$ & $\mathrm{P}=0.971$ \\
\hline \multicolumn{5}{|l|}{ Gender } \\
\hline Male (N (\%)) & $25(16.4)$ & $8(10.3)$ & $17(23.0)$ & \multirow{2}{*}{$\mathrm{P}<0.05$} \\
\hline Female (N (\%)) & $127(83.6)$ & $70(89.7)$ & $57(77.0)$ & \\
\hline \multicolumn{5}{|l|}{ Municipality of work } \\
\hline Suburban $(\mathrm{N}(\%))$ & $21(13.8)$ & $11(14.1)$ & $10(13.5)$ & \multirow{3}{*}{$\mathrm{P}=0.935$} \\
\hline Broader city $(\mathrm{N}(\%))$ & $108(71.1)$ & $56(71.8)$ & $52(70.3)$ & \\
\hline Central city $(\mathrm{N}(\%))$ & $23(15.1)$ & $11(14.1)$ & $12(16.2)$ & \\
\hline \multicolumn{5}{|l|}{ Primary healthcare department } \\
\hline School pediatrics $(\mathrm{N}(\%))$ & $78(51.3)$ & - & - & - \\
\hline Gynecology (N (\%)) & $74(48.7)$ & - & - & - \\
\hline \multicolumn{5}{|l|}{ Number of patients per shift } \\
\hline$<30(\mathrm{~N}(\%))$ & $18(11.8)$ & $2(2.6)$ & 16 (21.6) & \multirow{3}{*}{$\mathrm{P}<0.001$} \\
\hline $30-40(\mathrm{~N}(\%))$ & $79(52.0)$ & $28(35.9)$ & $51(68.9)$ & \\
\hline$>40(\mathrm{~N}(\%))$ & $55(36.2)$ & $48(61.5)$ & $7(9.5)$ & \\
\hline \multicolumn{5}{|l|}{ Number of adolescent patients } \\
\hline $0-5$ per month $(\mathrm{N}(\%))$ & $24(15.8)$ & 0 & $24(32.4)$ & \multirow{4}{*}{$\mathrm{P}<0.001$} \\
\hline $1-5$ per week $(\mathrm{N}(\%))$ & $33(21.7)$ & $2(2.6)$ & $31(41.9)$ & \\
\hline $1-5$ per day $(\mathrm{N}(\%))$ & $54(35.5)$ & $36(46.2)$ & $18(24.3)$ & \\
\hline Almost all (N (\%)) & $40(26.3)$ & $40(51.3)$ & 0 & \\
\hline \multicolumn{5}{|l|}{ Having an adolescent child } \\
\hline Yes $(\mathrm{N}(\%))$ & $36(23.7)$ & $15(19.2)$ & $21(28.4)$ & \multirow{2}{*}{$\mathrm{P}=0.252$} \\
\hline No $(\mathrm{N}(\%))$ & $116(76.3)$ & $63(80.8)$ & $53(71.6)$ & \\
\hline
\end{tabular}

tt-test and Chi-square test. 
of participants were female $(83.6 \%)$ and working in the broader city municipalities. However, statistically larger number of gynaecologists were males compared with paediatricians (23\% vs. $10.3 \%$, $\mathrm{P}<0.05)$. Moreover, respondents from the paediatricians group significantly differed from the respondents from the gynaecology group with respect to the number of patients per shift $(\mathrm{P}<0.001)$. In the group of school paediatricians, the majority of respondents had over 40 patients per shift (61.5\%), which was significantly higher compared with the group of gynaecologists where the largest number of respondent had between 30 and 40 patients per shift $(68.9 \%)$. A significant difference between paediatricians and gynaecologists was observed regarding the proportion of adolescent patients $(\mathrm{P}<0.001)$. Almost all patients were adolescents in school health departments, whereas in the gynaecology departments, the majority of respondents attended 1 to 5 adolescent patients per week.

\section{Factors that Jeopardize Adolescents' Right to Confidentiality in Healthcare}

The distribution of the respondents according to a level of agreement with items in the questionnaire according to the department of work is presented in Table 2. Although the original 5-pointscale was applied, the responses "Strongly agree" and "Agree" were merged, as well as the responses "Strongly disagree" and "Disagree".

More than a half of the respondents $(51.3 \%)$ agreed that insufficient number of physicians could be the factor facilitating breach of confidentiality while working with adolescents. Similarly, most physicians in the total sample $(67.1 \%)$ considered a lack of time per patient as a factor that facilitates breach of confidentiality. Also, more than one half of the respondents agreed that a lack of a gynaecologist that will solely be dedicated to healthcare of adolescent girls is a significant barrier to respect-

\begin{tabular}{|c|c|c|c|c|c|}
\hline \multirow{2}{*}{ Factors that threaten confidentiality in adolescent healthcare } & \multirow{2}{*}{$\begin{array}{l}\text { Level of } \\
\text { agreement }\end{array}$} & \multirow{2}{*}{$\begin{array}{l}\text { Paediatrics } \\
\mathrm{N}(\%)\end{array}$} & \multirow{2}{*}{$\begin{array}{l}\text { Gynecology } \\
\mathrm{N}(\%)\end{array}$} & \multirow{2}{*}{$\begin{array}{l}\text { Total } \\
\mathrm{N}(\%)\end{array}$} & \multirow{2}{*}{ P-value f $^{\ddagger}$} \\
\hline & & & & & \\
\hline \multirow{3}{*}{ F1- Insufficient number of physicians per shift } & Disagree & $31(39.7)$ & $35(47.3)$ & $66(43.4)$ & \multirow{3}{*}{$\mathrm{P}=0.62$} \\
\hline & Neutral & $4(5.1)$ & $4(5.4)$ & $8(5.3)$ & \\
\hline & Agree & $43(55.1)$ & $35(47.3)$ & $78(51.3)$ & \\
\hline \multirow{3}{*}{ F2- Lack of time per patient } & Disagree & $18(23.1)$ & $23(31.1)$ & $41(27.0)$ & \multirow{3}{*}{$\mathrm{P}=0.54$} \\
\hline & Neutral & $5(6.4)$ & $4(5.4)$ & $9(5.9)$ & \\
\hline & Agree & $55(70.5)$ & $47(63.5)$ & $102(67.1)$ & \\
\hline \multirow{3}{*}{ F3- Inadequate protection of medical records } & Disagree & $27(34.6)$ & $34(45.9)$ & $61(40.1)$ & \multirow{3}{*}{$\mathrm{P}=0.29$} \\
\hline & Neutral & $11(14.1)$ & $11(14.9)$ & $22(14.5)$ & \\
\hline & Agree & $40(51.3)$ & $29(39.2)$ & $69(45.4)$ & \\
\hline \multirow{3}{*}{$\begin{array}{l}\text { F4- Inadequate information on legal obligations of physicians to } \\
\text { protect patients' rights }\end{array}$} & Disagree & $23(29.5)$ & $28(37.8)$ & $51(33.6)$ & \multirow{3}{*}{$\mathrm{P}=0.38$} \\
\hline & Neutral & $20(25.6)$ & $13(17.6)$ & $33(21.7)$ & \\
\hline & Agree & $35(44.9)$ & $33(44.6)$ & $68(44.7)$ & \\
\hline \multirow{3}{*}{ F5- Parental insisting to be informed on their child's health } & Disagree & $20(25.6)$ & $28(37.8)$ & $48(31.6)$ & \multirow{3}{*}{$\mathrm{P}=0.30$} \\
\hline & Neutral & $26(33.3)$ & $16(21.6)$ & $42(27.6)$ & \\
\hline & Agree & $32(41.0)$ & $30(40.5)$ & $62(40.8)$ & \\
\hline \multirow{3}{*}{ F6- Insufficient education in adolescent medicine in physicians } & Disagree & $19(24.4)$ & $22(29.7)$ & $41(27.0)$ & \multirow{3}{*}{$\mathrm{P}=0.75$} \\
\hline & Neutral & 21(26.9) & $18(24.3)$ & $39(25.7)$ & \\
\hline & Agree & $38(48.7)$ & 34 (45.9) & $72(47.4)$ & \\
\hline \multirow{3}{*}{$\begin{array}{l}\text { F7- Unavailability of the gynecologist appointed solely to the } \\
\text { work with adolescents }\end{array}$} & Disagree & $15(19.2)$ & 33 (44.6) & 48 (31.6) & \multirow{3}{*}{$\mathrm{P}=0.002$} \\
\hline & Neutral & $7(9.0)$ & $7(9.5)$ & $14(9.2)$ & \\
\hline & Agree & $56(71.8)$ & $34(45.9)$ & $90(59.2)$ & \\
\hline \multirow{3}{*}{$\begin{array}{l}\text { F8- Inaccurate legal definition of situations of "serious threat to } \\
\text { life and health" in which parents must be informed against the } \\
\text { will of the child. }\end{array}$} & Disagree & $14(17.9)$ & $18(24.3)$ & $32(21.1)$ & \multirow{3}{*}{$\mathrm{P}=0.62$} \\
\hline & Neutral & $21(26.9)$ & $19(25.7)$ & $40(26.3)$ & \\
\hline & Agree & $43(55.1)$ & $37(50.0)$ & $80(52.6)$ & \\
\hline
\end{tabular}

"School paediatrics department; Gynecology department; ${ }^{\ddagger}$ Chi-square test. 
ing confidentiality - significantly higher proportion of paediatricians agreed on this item compared to gynaecologists ( $71.8 \%$ vs. $45.9 \%, \mathrm{P}=0.002)$. Nearly a half of all respondents agreed that medical records are inadequately protected (45.4\%), and that healthcare professionals are inadequately informed about their legal obligations towards adolescent patients (44.7\%). Similar proportions of respondents agreed that parental demand to be informed about their children's health facilitates breach of confidentiality (40.8\%), as well as insufficient education in adolescent medicine (47.4\%). More than a half of the respondents believed that the legal definition of situations where physicians have to inform the parents, because health and life of a minor is seriously endangered, is not precise enough (52.6\%), leaving the decision to the discretion of an individual physician, and therefore, potentially breach confidentiality. The average total score on the scale in the total sample was $26.05 \pm 7.017$ out of 40 .

\section{Linear Regression Analysis}

Univariate and multivariate linear regression were used to determine whether socio-demographic characteristics of the respondents predicted their experience of obstacles to providing confidential services to adolescents. Socio-demographic variables were entered first into the univariate linear regression models, with total score of the questionnaire being the independent variable. Variables Department and Number of adolescent patients showed a significant association with the total score in the univariate analyses (Table 3). These two variables were entered into the multivariate linear regression model together with the variables Age and Gender, since age and gender are the most important socio-demographic characteristics in the assessments of attitudes.

The total variance explained by the multivariate model as a whole was $8.2 \%$ ( $\mathrm{R}$ square $=0.082$, $\mathrm{F}=3.267, \quad \mathrm{P}=0.013$ ) (Table 4). The multivariate model significantly explained the outcome variable. None of the independent variables in the multivariate model showed significant association with the total score of the questionnaire on Factors that threaten confidentiality (Table 5).

Table 4. Characteristics of the Multiple Linear Regression Model

\begin{tabular}{lllll}
\hline $\mathrm{R}$ & $\mathrm{R}$ square & Adjusted R square & $\mathrm{F}$ & $\mathrm{P}$ - value \\
\hline 0.284 & 0.081 & 0.055 & 3.199 & $<0.05$ \\
\hline
\end{tabular}

"Multiple linear regression.

Table 5. Characteristics of Factors Associated with the Total Score on Factors that Threaten Confidentiality Scale

\begin{tabular}{lllll}
\hline Variable & $\mathrm{B}$ & $\beta$ & $\mathrm{t}$ & $\mathrm{P}$-value \\
\hline Constant & 32.613 & & 4.661 & $<0.001$ \\
\hline Age & -0.074 & -0.095 & -1.184 & 0.238 \\
\hline Gender & -2.145 & -0.112 & -1.376 & 0.171 \\
\hline Department & -1.304 & -0.093 & -0.742 & 0.459 \\
\hline $\begin{array}{l}\text { Number of adolescent } \\
\text { patients }\end{array}$ & 1.142 & 0.166 & 1.338 & 0.183 \\
\hline
\end{tabular}

*Multiple linear regression.

Table 3. Characteristics of the Univariate Linear Regression Models

\begin{tabular}{lllllllllll}
\hline Variable & $\mathrm{R}$ & R square & Adjusted R square & $\mathrm{F}$ & $\mathrm{P}$-value & $\mathrm{B}$ & $\beta$ & $\mathrm{t}$ & $\mathrm{P}$-value \\
\hline Age & 0.125 & 0.016 & 0.009 & 2.384 & 0.125 & -0.097 & -0.125 & -1.544 & 0.125 \\
\hline Years after graduation & 0.113 & 0.013 & 0.006 & 1.923 & 0.168 & -0.079 & -0.113 & 0.278 & 0.168 \\
\hline Gender & 0.088 & 0.008 & 0.001 & 1.182 & 0.279 & -1.668 & -0.088 & -1.087 & 0.279 \\
\hline Municipality of work & 0.012 & 0.000 & -0.007 & 0.023 & 0.879 & -0.161 & -0.012 & -0.152 & 0.879 \\
\hline Department & 0.206 & 0.042 & 0.036 & 6.641 & $<0.05$ & -2.881 & -0.206 & -2.577 & $<0.05$ \\
\hline No of patients per shift & 0.139 & 0.019 & 0.013 & 2.949 & 0.088 & 1.457 & 0.139 & 1.717 & 0.088 \\
\hline No of adolescent patients & 0.236 & 0.055 & 0.049 & 8.808 & $<0.05$ & 1.550 & 0.236 & 2.968 & $<0.05$ \\
\hline Having an adolescent child & 0.039 & 0.002 & -0.005 & 0.229 & 0.633 & 0.643 & 0.039 & 0.479 & 0.633 \\
\hline
\end{tabular}

Univariate linear regression. 


\section{Discussion}

Despite being an important aspect of the effective adolescent healthcare, keeping sensitive information confidential is often sub-optimal, due to various systemic and personal factors. Most respondents in this study agreed with factors that have previously been identified such as the violation of adolescents' right to confidentiality in practice (16, 17). Univariate linear regression analyses showed that the department of work (gynaecology or paediatrics) and the number of adolescent patients were significantly associated with a higher score on the Factors that threaten confidentiality scale. Also, respondents from the paediatrics department saw significantly more adolescent patients compared to gynaecologists. These results suggest that greater involvement with adolescent patients renders physicians more sensitive to the issue of confidentiality as well as cognizant of the barriers to maintaining confidentiality.

Not having sufficient time for each patient was recognized by the majority of the respondents as one of the factors that facilitate breach of confidentiality in contact with adolescents. A lack of time restricts the opportunities to have an in-depth conversation about sensitive topics which necessary in order to establish a confidential relationship with adolescent patients. The issue of time constraints has been recognized in other studies focusing on attitudes of healthcare professionals towards confidentiality $(16,17)$. In a qualitative study of perspectives of primary care clinicians from New York on challenges of providing confidential care to adolescents, almost all of the respondents emphasized time constraints as the main barrier to offering time alone to adolescent patients more consistently (16). Time constraints limit the opportunity for physicians to discuss sensitive issues in more depth as well as to recognize risk behaviours and psychosocial problems. A survey conducted among family doctors from Spain found that doctors with heavy workload tend to inform parents to a greater extent, because they had limited time to focus their attention to each individual adolescent patient (17).
Time constraints are inevitably associated with an insufficient number of physicians in healthcare facilities. There are several reasons for the decline in the number of primary healthcare physicians in Serbia. Decreasing wages in the public health sector, as one of the unfavourable consequences of the socio-economic transition in Serbia, has led to the continuing, increasing emigrations of healthcare professionals to more developed countries worldwide, which has been the trend in all countries of the Western Balkans (18). Another reason for the decline in the number of primary healthcare physicians is the restrictive employment policy in the health sector in previous years (19). A shortage of healthcare workers requires a systematic approach to the planning of human resources in healthcare.

Our respondents have recognized inadequate protection of medical records as an issue of concern. In Serbia, electronic medical records are shared among all services within the primary healthcare system, with confidential information being accessible to all primary care specialists. This means that a patient's electronic record might be accessed from any computed within the healthcare computer system. Nevertheless, the use of electronic health records, hinders the possibility of separating or "hiding" the sensitive information from being visible to all persons who have access medical records (20). Results of a qualitative study among American paediatricians showed that the strategies to keep the electronic medical records confidential vary, from completely omitting the sensitive information to strategic coding of the confidential data (20).

To keep medical records confidential, we suggest that additional electronic tools are developed and implemented to conceal sensitive information in the medical records. In this way, confidential information would only be accessible to those healthcare professional to whom it was disclosed. Adolescent patients should decide about the extent of confidential information that is allowed to be shared with other health professionals or parents. In addition, healthcare professionals would benefit from additional training to improve their technical skills while using electronic medical records. 
Inadequate knowledge of legal regulations among healthcare providers is often recognized as a barrier to maintain service to adolescents confidential, since a number of physicians are unaware of their legal obligation relative to the patient's age $(21,22)$. In addition, even after being informed about the legal framework for adolescents' rights in healthcare, some physicians might have negative attitudes or require lengthy periods of time to implement the law into clinical practice (23). Thus, although legally granted, adolescents' rights seem to be continuously neglected in practice. In addition, our respondents agreed that additional barrier accounts for vague legal definition of circumstances when it is justified to breach confidentiality. For this reason, a decision to breach confidentiality remains at the discretion of a physician in question.

A lack of precise legal guidelines as to the circumstances when confidentiality must be prioritized in adolescent healthcare was emphasized as a barrier in other studies as well $(16,23)$. As a result, this issue caused confusing and inconsistent practice of keeping the adolescent information confidential. Organization of systematic legal education with precise legal guidelines along with continuing medical education could empower primary care physicians to accept adolescents' legal rights in healthcare and address the specific problems in adolescent healthcare in a more comprehensive manner.

Finally, a lack of a gynaecologist appointed solely for adolescents in primary healthcare institutions was emphasized as an obstacle to confidential care by more than one half of respondents. This finding highlights that ending youth-friendly counselling services in the Serbian primary healthcare institutions due to a shortage of financial and human resources was not a favourable strategy. At the Cairo International Conference on Population and Development in 1994, the goals to improve adolescent access to reproductive health services and education were adopted, underscoring the need to adapt the health programs and the very characteristics of healthcare services (working hours, physical separation, and guarantee of confidentiality) to the needs of adolescents (24). The Cairo conference goals facilitated the implementation of youth-friendly health services in health systems worldwide. Experiences of countries where youth-friendly approach has taken hold showed significant improvements in adolescent health. For example, in the United Kingdom the rate of adolescent pregnancies has decreased since 1970-ies (25).

In Serbia, youth friendly counselling services within primary healthcare institutions were established in 1999. These services were focused on the health of adolescents, and integrated multidisciplinary approach for different health problems: reproductive health, mental health, substance abuse, developmental issue, family issues, and included specialists in fields of gynaecology, paediatrics, psychology and social work. Youth friendly approach was supported in two recently adopted national strategic documents (The Strategy for the Encouragement of Childbirth, The Decree on the National Program for Safeguarding and Improving Sexual and Reproductive Health of the Citizens of the Republic of Serbia) (26, 27). However, most youth friendly counselling services in Serbia were closed down over the past decade due to a shortage of healthcare professionals who could commit part of their working hours to this service. Moreover, the reform of the national health system in Serbia introduced the concept of a "chosen doctor", which prevents doctors working in youth friendly counselling services from charging their service from health insurance fund. The lack of financial compensation certainly discourages primary care physicians who regularly have heavy workload to participate in this kind of program. Adolescent girls who require reproductive health services are usually referred to the gynaecology departments within primary care institutions or to the adolescent gynaecologists within the children's hospital. However, these referral centres are not easily accessible to adolescent girls from municipalities living in the greater metropolitan area.

Since keeping the reproductive health services confidential is of vital importance for adolescent health, and for the health of the entire population, 
a strategic plan for re-opening of the sustainable youth-friendly counselling services should be passed at a national level. This is especially relevant because empirical evidence suggests that youth-friendly counselling services are the most effective approach when addressing health issues in adolescence (28).

Investments in adolescent healthcare should not be neglected, regardless of the level of healthcare development. The Lancet's commission for adolescent health and wellbeing suggests that the investment in adolescent health is the key strategy for a sustainable development and progress, especially in the developing countries (29). Numerous analyses showed that benefits from interventions focused on health and well-being of adolescents include not only a transformation of adolescents' lives, but also socio-economic well-being of a society as a whole (29). Thus, enabling adolescents to easily access health services should be prioritized in the national health policy. Our findings might serve as a foundation for policy-makers to improve the circumstances to keep sensitive adolescent information confidential, as it is one of the key characteristics of a safe and supportive adolescent healthcare service.

The strengths of this study is the circumstance that paediatricians and gynaecologists from almost all primary healthcare centres in the Belgrade metropolitan area were included in this analysis. This means that the sample was representative of paediatricians and gynaecologists working in primary healthcare in Belgrade, but could also be applicable to other larger urban areas in Serbia. Another strength of this study is that only one study from Serbia previously explored the issue of confidentiality in adolescent healthcare settings (15). Therefore, the results of this study may provide directions as to how to improve the healthcare delivery for adolescents.

In terms of study limitations, only paediatricians and gynaecologists from the largest urban area of Serbia were included. Inclusion of paediatricians and gynaecologists who work in towns and rural areas could have had different view on the issue of confidentiality in adolescent healthcare services. This study was cross-sectional, which means that the regression model cannot provide precise assumptions of causality. Because none of the independent variables was associated with a higher score of Factors that threaten confidentiality scale, future studies should consider inclusion of other data related to work environment and personal preferences of the participants.

\section{Conclusion}

The results of this study highlight specific obstacles that need to be addressed in order to improve the practice of respect of confidentiality of adolescent patients. Physicians working with adolescents need to be well-informed about legal guidelines on rights of their adolescent patients, who do not have legal competence, but do have a decision-making capacity. Protection of electronic medical records also needs to be improved. One way to achieve this is to implement a specific option within the electronic medical system that will allow protection of confidential information. At a national level, addressing human resources in the healthcare sector could improve everyday encounters with adolescent patients, enabling physicians in the primary healthcare setting to dedicate more time to adolescent health issues, such as in-depth conversations. Finally, we consider that the concept of youth-friendly health services could be the best framework for maintaining health services to adolescents confidential.

Conflict of Interest: The authors declare that they have no conflict of interest.

Authors' Contributions: Conception and design: VJS, BM and SC; Acquisition, analysis and interpretation of data: VJS, SC, and TG; Drafting the article: VJS and SC; Revising it critically for important intellectual content: BM and TG; Approved final version of the manuscript: VJS, BM, SC and TG.

\section{References}

1. Delva W, Wuillaume F, Vansteelandt S, Claeys P, Verstraelen H, Temmerman M. Sexual behaviour and contraceptive use among youth in Balkans. Eur JContracept Reprod Health Care.2007;12:309-15.

2. Boričić K, Vasić M, Grozdanov J, Gudelj Rakić J, Živković Šulović M, Jahović Knežević N. Results of the National Health Survey in Serbia: 2013 [In Serbian]. Belgrade: 
Institute of Public health of Serbia "Dr Milan Jovanović Batut”; 2014.

3. World Health Organization. Situation of child and adolescent health in Europe. Copenhagen: World Health Organization; 2018.

4. United Nations Children's Fund (UNICEF). Young People in Changing Societies. Regional monitoring report 7. Florence: UNICEF Innocenti Research Centre; 2000.

5. Santhya KG, Jejeebhoy SJ. Sexual and reproductive health and rights of adolescent girls: evidence from low- and middle-income countries. Glob Public Health. 2015;10(2):189-221.

6. Wood DL, Hayward RA, Corey CR, Freeman HE, Shapiro MF.Access to medical care for children and adolescents in the United States. Pediatrics. 1990;86:666-73.

7. World Health Organization (WHO). Adolescent-Friendly Health Services: An Agenda for Change. Geneva: WHO, 2002.

8. Brittain AW, Williams JR, Zapata LB, Pazol K, Romero LM, Weik TS. Youth-friendly family planning services for young people: a systematic review. Am J Prev Med. 2015;49(2):S73-84

9. Elster AB, Kuznets NJ. The American Medical Association Guidelines for Adolescent Preventive Services (GAPS): Recommendations and rationale. Baltimore: Williams and Wilkins, 1994.

10. Ford C, English A, Sigman G. Confidential health care for adolescents: Position paper of the Society for Adolescent Medicine. J Adolesc Health. 2004;35:160-7.

11. American Academy of Pediatrics. Confidentiality protections for adolescents and young adults in the health care billing and insurance claims process. J Adolesc Health. 2016;58(3):374-7.

12. American Medical Association (AMA). AMA Code of Medical Ethics. Opinion 5.055: Confidential Care for Minors. American Medical Association, 2014. Available at https://journalofethics.ama-assn.org/article/ama-codemedical-ethics-opinion-adolescent-care/2014-11 (Accessed on 01 October 2018).

13. Brittain AW, Williams JR, Zapata LB, Moskosky SB, Weik TS. Confidentiality in family planning services for young people: a systematic review. Am J Prev Med. 2015;49(2):S85-92.

14. Wadman R, Thul D, Elliott AS, Kennedy AP, Mitchell I, Pinzon JL. Adolescent confidentiality: Understanding and practices of health care providers. Paediatric Child Health. 2014;19(2):e11-e14.

15. Jeremic Stojkovic V, Matejic B, Turza K. Serbian primary care physicians' perspectives on adolescents' right to confi- dentiality in sexual and reproductive healthcare-a qualitative interview study. Fam Pract. 2018;36(3):317-24.

16. McKee MD, Rubin SE, Campos G, O'Sullivan LF. Challenges of Providing Confidential Care to Adolescents in Urban Primary Care: Clinician Perspectives. AnnFam Med. 2011;9(1):37-43.

17. Pérez-Cárceles MD, Pereñiguez JE, Osuna E, Pérez-Flores D, Luna A. Primary care confidentiality for Spanish adolescents: fact or fiction? J Med Ethics. 2006; 32(6):329-34.

18. Lazarevik V, Kongjonaj A, Krstic M, Malowany M, Tulchinsky T, Neumark Y. Physicians Migration from Western Balkan. Eur J Public Health. 2016;26(Suppl1):132-3.

19. Law on the maximum number of public sector employees. „Gazette RS“, no. 68/2015, 81/2016

20. Stablein T, Loud KJ, DiCapua C, Anthony DL. The catch to confidentiality: the use of electronic health records in adolescent health care. J Adolesc Health. 2018;62(5):57782 .

21. Riley M, Ahmed S, Reed BD, Quint EH.Physician Knowledge and Attitudes around Confidential Care for Minor Patients.J PediatrAdolescGynecol. 2015;28:234-9.

22. Lazarus JV, Jaruseviciene L, Liljestrand J. Lithuanian general practitioners' knowledge of confidentiality laws in adolescent sexual and reproductive healthcare: A crosssectional study. Scandi J Public Health. 2008;36(3):303-9.

23. Jaruseviciene L, Levasseur G, Liljestrand J. Confidentiality for adolescents seeking reproductive health care in Lithuania: the perceptions of general practitioners. Reproduct Health Matters. 2006;14(27):129-37.

24. United Nations Department of Public Information. Programme of action. In: International Conference on Population and Development; September 5-13, 1994; Cairo, Egypt. Available at: https:// www. unfpa. org/ sites/ default/ files/ event- pdf/ PoA_ en. pdf. (Accessed on 06 December, 2018).

25. Ingham R, Chandra-Mouli V. Implementing the United Kingdom's ten-year teenage pregnancy strategy for England (1999-2010): How was this done and what did it achieve? Reprod Health. 2016;13(1):139.

26. World Health Organization. Youth Friendly Health Policies and Services in European Region: Sharing Experience 2010. Available at: http://apps.who.int/iris/bitstream/ handle/10665/107284/E94322.pdf?sequence=1 (accessed on 03 December 2019).

27. Sheehan P, Sweeny K, Rasmussen B, Wils A, Friedman HS, Mahon J, et al. Building the foundations for sustainable development: a case for global investment in the capabilities of adolescents. Lancet. 2017;390(10104):1792-806. 